\title{
Sir Richard Doll, 1912-2005
}

\author{
D Simpson
}

Tobacco Control 2005;14:289-290. doi: 10.1136/tc.2005.014027

$\mathrm{S}$ ir Richard Doll, the medical research scientist whose findings provided some of the most important foundations of tobacco control, died peacefully on 24 July 2005 , aged 92. While his name is most notably linked to epidemiological studies demonstrating the link between tobacco and disease, his research ranged much more widely, including asbestos, ionising radiation, and clinical trials of therapies to prevent and treat cardiovascular disease and cancer. Apart from his work, continuing until just weeks before his death, his other interests were equally diverse, as a forthcoming biography by Conrad Keating will describe.

Doll is probably best known to tobacco control advocates for his prospective study of British doctors. This was started in 1951 in collaboration with his mentor, the medical statistician Sir Austin Bradford Hill, and continued for the last 30 years with Sir Richard Peto (Doll in turn was Peto's mentor). It ran for 50 years, revealing new and important information in every report, and ranks as among the greatest prospective epidemiological studies ever undertaken. The early results of this and the 1950 case control study that prompted it provided some of the most important data reviewed in the first report on smoking of the Royal College of Physicians of London, published in 1962, which in turn led to the first US Surgeon General's report on the subject two years later.

The young Richard Doll intended to be a mathematician, but as he liked to recount, a surfeit of strong college beer before his final scholarship exam at Cambridge left him with a lesser offer than he had hoped for, so he followed his father into medicine. From the first, in pre-National Health Service Britain, he was concerned about inadequate health care, housing, and other social conditions among the poor, and became politically active. As fascism threatened Europe, early pacifism gave way to a sense of duty to fight it, and he enlisted into the army medical corps, seeing active service in France and Egypt.

After suffering renal tuberculosis and the removal of one kidney, Doll began a post-war hospital career during which he enrolled in a course by Bradford Hill, father of medical statistics, which perfectly combined his interests in mathematics and public health. Hill was impressed and asked Doll to work for him, setting in train a long and brilliant career in epidemiology and randomised controlled trials. Sir Richard was awarded many prizes for his work, most recently the Shaw Prize in Life Science and Medicine and, together with Sir Richard Peto, the King Faisal award for medicine.

Sir Richard's lifelong commitment to medical research is exemplified by a recent meeting in which frustrated researchers discussed increasing restrictions on access to patient records. Probably the only nonagenarian present, he remained silent through most of the meeting, then said quietly, "If it was thought to serve a useful purpose, I would be quite prepared to go to prison over this..."- -and he meant it.

As president of Action on Smoking and Health (ASH), he was always supportive to its staff, but exercised a prudent restraint on deeper involvement with its campaigning, to maintain his independence as a scientist providing the underlying evidence. However, as years of relative inaction

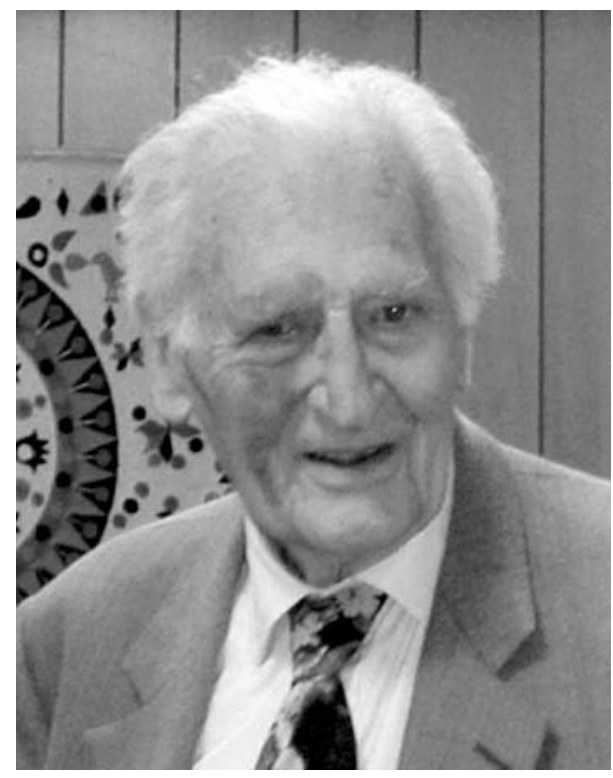

Professor Sir Richard Doll. Photograph: David Simpson.

went by, he became increasingly outspoken and used every opportunity to put the message across to the media. He also became more concerned about passive smoking, moving from a position based on his own tolerance of it, and the significantly greater risk of active smoking, to providing a strong statement backing ASH's call for a workplace smoking ban.

From 1969 Doll was based in Oxford, variously as Regius Professor of Medicine, director of a renowned medical research unit, where he helped train many of the next generation of medical researchers, and establishing and becoming first warden of Green College. After retirement he retained an office in his old unit, and until its move earlier this year, could still be seen climbing two flights of stairs to it every day, when not speaking at scientific meetings around the world. Happily, he lived to occupy an office in the unit's new home, the splendid Richard Doll Building. He continued to be a superb chairman of numerous scientific committees, sometimes involving international telephone conferences of several hours.

The rest of Sir Richard's life was fuller than many with a tenth of his output. He enjoyed a long and happy marriage to Joan, née Faulkner, until her death in 2001. Clever, humorous and twinkle eyed, with her owl-like spectacles and fizzing enthusiasm for life, Joan shared not only his values and his style, but his many interests, too, including his passion for travel. While missing Joan greatly, Sir Richard continued to travel after her death. The last year of his life saw him in Spain, Hong Kong, Saudi Arabia, Sweden and Australia, and still enjoying new experiences, such as island hopping in the second pilot's seat last year in Orkney, and flying in a glider earlier this year in Australia. 
Doll was an avid reader, especially the modern novel. Receiving an honorary degree at Aberdeen last year, his told graduating doctors that their medical education had taught them about the body, but if they wanted to know about human beings, they should read novels. He also enjoyed biography, travel writing and history-he had lived through so much of it, and kept well briefed on current affairs, with an unusually open, fair, non-judgemental mind. He was a superb raconteur with great charm and humour, and a seemingly bottomless fund of stories. He was as captivating addressing a large scientific conference, with his elegant, succinct style spiced with wit, as he was in conversation with friends over a quiet pint of beer at weekends. He had great style and dressed well, with a fine collection of ties.
Days before he entered hospital, he attended the Green College summer dinner, a fine figure in a white tuxedo, charming friends young and old, and enthusing about the new building that bears his name. He drew envious glances from men, who told each other they would be happy to be half as active at 70, never mind 90, and admiring glances from women, some joking with each other that given the chance, they would leave home for him. Sir Richard Doll used to say that he wanted to die young as old as possible. That is exactly what he did; and thanks to his life's work, millions of others have the chance of doing the same.

Correspondence to: David Simpson, d.simpson@iath.org 